Docência na contemporaneidade: desafios para docentes no ensino superior | 233

\title{
DOCÊNCIA NA CONTEMPORANEIDADE: DESAFIOS PARA DOCENTES NO ENSINO SUPERIOR
}

\author{
Ricardo Santos David ${ }^{82}$
}

RESUMO: Este artigo fala sobre os desafios do trabalho docente no ensino superior e sobre as práticas docentes necessárias para que as ações de ensinar e de aprender sejam verdadeiramente realizadas de forma a possibilitar a construção do conhecimento no ambiente da instituição de ensino superior na atualidade. Aqui são mostrados os desafios perante os alunos de hoje devido às suas mudanças de comportamentos, de prioridades e da importância que dão para a aprendizagem formal. Questões como: o que é ensinar e o que é aprender nos dias atuais, quais estratégias de ensinagem são necessárias para o efetivo aprendizado dos alunos, quais características o docente precisa apresentar para ser considerado um profissional competente, como está o ensino superior na atualidade, quem são os alunos ingressantes no ensino superior e o que buscam e como estes alunos se relacionam com os professores e com a instituição de ensino superior na Era da Informação, estão presentes neste artigo.

Palavras-chave: Educação Superior; Atuação Docente; Modernidade.

ABSTRACT: This article talks about the challenges of teaching in higher education and on teaching practices necessary for the actions of teaching and learning are truly made in order to enable the construction of knowledge in the institution of higher education in today environment. Here are shown the challenges students face today due to their behavioral changes, priorities and the importance they attach to formal learning. Questions like: what teaching and learning is that nowadays, teaching and learning strategies which are necessary for effective student learning, which features the teacher must fulfill to be considered a competent professional, as is higher education today, who are commencing students in higher education and what students want and how they relate to the teachers

Keywords: higher education; Teacher performance; Modernity.

\footnotetext{
${ }^{82}$ Doutorando em Educação: Formação de Professores, pela UNIATLANTICO. Especialista em linguistica aplicada e literatura. Professor de lingua portuguesa e inglesa para o ensino fundamental.
} 


\section{INTRODUÇÃO}

As sociedades modernas, principalmente aquelas baseadas no sistema capitalista, exigem dos indivíduos que ela integra, cada vez mais quando se trata de rendimento, excelência, produtividade e qualidade, principalmente quando se trata do mercado de trabalho. Isso contribui consequentemente, como aumento da competição acirrada dentro dessa sociedade fazendo com que cada pessoa, de todas as profissões tenha que estar cada vez mais configurados às novas demandas impostas pelos moldes capitalistas de trabalho.

Essas demandas, por muitas vezes, não são remuneradas de acordo com o tempo e trabalho gasto para atendê-las, ou mesmo, o profissional se quer é reconhecido pelo seu trabalho. É possivel observar, portanto, neste contexto que os males sociais cada vez mais aumentam, atingindo cada indivíduo envolvido neste sistema e, como consequência, estes desenvolvem problemas físicos e psicológicos que influenciam em seu desenvolvimento tanto pessoal quanto profissional.

A cada dia que passa exige-se cada vez mais do docente: trabalho docente de qualidade, trabalho administrativo dentro do prazo, observação às dificuldades e particularidades dos alunos em sala de aula, atendimento a pais de alunos, melhoria em sua qualificação profissional através de cursos de especialização - sendo que estes, muitas vezes, são pagos pelo próprio docente - dentre outras exigências. E tais demandas nem sempre são recompensadas, pelo menos financeiramente, conforme o tempo e trabalho despendido pelo docente. Dessa forma, o docente, em tentar complementar sua renda, procura uma segunda jornada de trabalho e acumula ainda mais trabalho, estresse dentre outras problemáticas.

Os profissionais do ensino superior precisam ter consciência do que representa estar na universidade atualmente. Para muitos alunos, a oportunidade única ainda, mas por estar em um país onde as desigualdades sociais se refletem na educação, tendo um papel social essencial no desenvolvimento do pais, sociedade e história contemporânea.

Por esse motivo são lançadas algumas perguntas como: Quem é o docente universitário de hoje? Qual o perfil exigido?

O objetivo principal deste trabalho de pesquisa é buscar, da pesquisa documental e bibliográfica, a compreensão e possiveis respostas 
Docência na contemporaneidade: desafios para docentes no ensino superior | 235

para estas perguntas sobre a necessária formação e atuação para o docente na educação superior na atualidade.

\section{O PAPEL DO DOCENTE NA MODERNIDADE}

O objetivo deste capítulo é tratar, brevemente, sobre o papel do docente no processo de ensino e aprendizagem e na educação de forma geral, entendendo o que a sociedade espera do mesmo, suas atribuições e exigências realizadas pelos tempos modernos. Esse resgate se faz necessário para que se entenda a real importância do docente no processo educacional e a razão pela qual ele necessita ser reconhecido, que seu trabalho seja moderado com suas funções de educar, salvaguardando sua qualidade de vida pessoal e profissional.

Pode-se observar, portanto, que atualmente o papel e a atuação do docente não é a mesma que no início e meio do século passado. Neste tempo, segundo Saviani (2008), o docente, sob um prisma tradicionalista, tinha o papel de detentor de todo o conhecimento e depositava nos seus alunos aquilo que havia estudado configurando o que o autor falar de “educação bancária”. (FONSECA, 2003.)

Atualmente, pode-se perceber que o docente mudou sua forma de atuação, seja porque os paradigmas educacionais mudaram ou a própria formação do docente mudou. Hoje, o docente é um facilitador no processo de ensino e aprendizagem, pois o ator principal neste processo é o aluno e o docente deve ensiná-lo a pensar, a questionar e a aprender a ler sua realidade, para que possam construir opiniões próprias.

Para que isto ocorra o docente deve, em primeiro lugar, gostar e acreditar naquilo que faz, ou seja, através de seus atos e ações ele servirá de modelo para seus alunos; se ele ensina a refletir ele deve também refletir, se ele ensina a respeitar o próximo ele deve respeitar seus alunos e assim por diante. Deste modo ele está sendo uma prova viva daquilo que está ensinando, pois bem a sua frente existem seres humanos que estão sendo moldados por ele.

A relação docente/aluno deve ser cultivada a cada dia, pois um depende do outro e assim os dois crescem e caminham juntos. E é nessa relação madura que o docente deve ensinar que a aprendizagem não ocorre somente em sala de aula. Assim, o aluno irá desenvolver um espírito pesquisador e interessado pelas coisas que existem; ele desenvolverá uma necessidade por aprender, tornando-se um ser questionador e crítico da realidade que o circunda (FREIRE, 1996, p. 34). 
Dessa forma e diante da quantidade de informações e da facilidade de acesso a estas, deve o docente conduzir o aluno de forma que possa o aprendizado ser mútuo e repleto de motivação. O docente deve "traduzir" os conteúdos de forma que o aluno se sinta dentro de uma inesquecível "viagem" e dessa forma possa assegurar a produtividade do ensinamento.

O distanciamento entre docente e aluno deve dar lugar a uma relação de proximidade e cumplicidade. Uma proximidade tal que aluno seja levado a querer aprender. A desejar sempre mais e que o educador sinta-se como um elemento de importância fundamental na vida daquele aluno que levará para sempre os ensinamentos adquiridos.

Os docentes devem ser preparados para a arte do ensinar. Não basta ser um bom pesquisador, necessário se faz que seja, também, um bom docente, ou seja, que saiba ensinar e facilitar a construção do conhecimento, ter um bom ou ótimo conhecimento sobre as especificidades do processo de ensino e aprendizagem. (NÓVOA, 2007.)

Existem profissionais extremamente habilitados para militar em suas respectivas áreas e ainda munidos de profundo conhecimento, entretanto limitados quando o assunto é transmitir seus conhecimentos e trabalhar em conjunto com o aluno. Muitas vezes o docente possui conhecimento, mas não sabe ensinar $\mathrm{e}$, muitas vezes, não procurar aprender, se aperfeiçoar.

Enfim, o docente deve ser um aliado na construção do indivíduo e não, simplesmente, um transmissor de disciplinas. $O$ docente deve ainda estar apto às contínuas mudanças do cotidiano, e na realidade do próprio aluno, auxiliando na formação de cidadãos conscientes de seus direitos e deveres.

É possivel observar ainda em outras pesquisas como a de Ruiz (2003) que diz que o docente deve assumir o papel de transformador social e, ainda, que é um ser e profissional político, que deve engajar-se política e socialmente a fim de desenvolver um processo de aprendizagem mais rico e realmente emancipador aos seus alunos.

Existem na própria sociedade outras exigências ao docente. $\mathrm{O}$ docente não possui somente o papel de educador, de facilitador no processo de ensino e aprendizagem, mas como um administrador das tarefas burocráticas - fazer provas, corrigi-las, passar nota, fazer exames, etc - e também como psicólogo que deve estar sempre em observação dos seus alunos atento a qualquer mudança de comportamento, tratar assuntos com os pais. Existem ainda as exigências de uma formação continuada, em que o docente deve estar constantemente se reciclando, fazendo cursos, se especializando e, muitas vezes, com seu próprio 
Docência na contemporaneidade: desafios para docentes no ensino superior | 237

dinheiro, pois muitas instituições não pagam nem se quer parcialmente os cursos realizados pelos docentes. E a remuneração não é condizente com tantas tarefas, tantas exigências, o que desestimula o docente, deteriorando não somente sua prática docente, bem como sua própria saúde.

\section{DOCENCIA NO ENSINO SUPERIOR}

A educação superior vem sendo muito debatida devido a grande importância e valorização do conhecimento e relação deste com o desenvolvimento econômico, político, social das sociedades. Podemos perceber através da nossa pesquisa que as instituições de ensino superior, estão em processo de reconstrução e reformulação referente a seu papel e função.

Cada vez mais é verificada a necessidade de uma reforma educacional em nosso país, para tornar capaz de promover a inclusão social e o desenvolvimento democrático em nossas instituições, possibilitando aos alunos o acesso e a permanência e aos docentes a possibilidade de pensar a educação superior hoje. A história da educação no Brasil nos revela que a formação do profissional superior e a sua atuação são importante, principalmente para a atualidade, em busca de uma educação e docência superior transformadora. (CUNHA, 2000)

Um desses questionamentos atuais é o novo rumo da formação docente. Tendo como desafio, a formação, revendo sua concepção, objetivos e funções, criando outras formas de desenvolver a formação continuada. (ABRAMOWICZ, 2001, p.137).

Atualmente o crescimento da profissão docente, é proporcional à valorização pela formação qualificada e conhecimento profissional mais aprofundado, através dos cursos superiores, da titulação exigida para um profissional considerado cada vez mais competente. Dessa forma, cabe também aos Programas de Pós-graduação proporcionar um espaço para a discussão e o pensar a formação e a atuação docente, o educador do ensino superior tem crescente interesse pela docência superior, exigências que estabelecem uma necessidade pessoal ou institucional de um profissional que compreenda e conheça a prática pedagógica, contexto e problemas da educação superior.

Os futuros profissionais da educação superior trazem consigo experiências escolares, constituindo em modelos, positivos ou negativas, de atuação docente, sendo parte importante da sua trajetória de vida. Apesar os docentes representem modelos, podemos verificar que é preciso 
muito mais para poder chegar a uma docência bem qualificada, na educação superior, resultando em um processo de construção e formação constantes.

profissional da educação superior não pode estar desatento à necessidade de uma educação transformadora, às exigências institucionais ou sociais do momento histórico, devendo procurar, refletir sobre qual é o seu papel e sua função, os limites e possibilidades de uma atuação transformadora.

\section{CONSIDERAÇÕES FINAIS}

Conforme visto no estudo o papel que o docente deve desempenhar numa sociedade moderna é complexo, diante das grandes demandas que a sociedade, de cunho capitalista, coloca sobre os profissionais e a todos os indivíduos de uma forma geral.

Exige-se, pela sociedade, desempenho, rendimento, habilidades para múltiplas tarefas, humanização, competição, etc. Ao mesmo momento que ao profissional é exigido que ele seja eficaz e que produza mais, em menos tempo, e com maior qualidade, que ele seja bem qualificado, exige-se que ele seja humano, que seja um ser social, um ser político, que esteja preparado para modificar sua realidade.

Com o docente, essas demandas são ainda maiores. Ao mesmo tempo em que este deve ser um educador, que hoje é considerado como um facilitador no processo de ensino e aprendizagem do aluno, ele também é, pelo menos em parte, um pouco psicólogo, pois deve observar as dificuldades dos alunos e da comunidade. $O$ docente deve realizar funções administrativas como confecção de provas, testes, passar notas, participar de reuniões pedagógicas, etc. $O$ docente deve, ainda, estar sempre atualizado, fazer cursos, se especializar, fazer mestrado, doutorado, etc. Não importando se ele possui recursos financeiros ou não para este fim. E ainda, o docente deve ser criativo em suas aulas sendo que estas devem ser de qualidade, motivadoras, que estimulem os estudantes a querer construir e/ou buscar o conhecimento.

Porém, quando chega a se recompensar o docente por todas essas exigências, pode-se dizer que este é um dos profissionais pior remunerados pelo o que o trabalho exige e pelo tempo despendido para o mesmo, sem falar do desgaste físico e emocional que é imposto ao docente. Com salários baixos, o docente procura mais trabalho para compensar sua renda, o que aumenta seu nível de estresse. $O$ docente 
Docência na contemporaneidade: desafios para docentes no ensino superior | 239

hoje é cobrado por um trabalho que deve ser coletivo, mas que, muitas vezes é possivel, por um aprofundamento intelectual e cultural que não tem acesso, diante das condições de trabalho limitadas; e por uma participação institucional não permitida, assim como por uma atuação didático-pedagógica de excelente qualidade.

Estes são desafios que permanecem para a construção das trajetórias docentes, construção esta que acontece individual e coletivamente, em diferentes contextos e condições, com outros seres humanos que estão participando das possiveis mudanças. Permanece a temporalidade do homem, um dia permanecerá apenas sua história, sua trajetória de vida, memórias, marca, influenciando outros homens, provocando e promovendo possíveis mudanças.

São de este olhar que se procurou compor este trabalho, das análises e reflexões de homens concretos, vivos, tecendo dia-a-dia suas histórias, suas trajetórias docentes, conscientes de sua participação no mundo. Propomo-nos apresentá-lo como contribuição para o aprofundamento das questões quanto ao papel da educação superior, das instituições e do profissional, educador em nivel superior.

\section{REFERÊNCIAS}

ABRAMOWICZ, Mere. A importância dos grupos de formação reflexiva docente no interior dos cursos universitários. In: CASTANHO, Sérgio; CASTANHO, Maria Eugênia. Temas e textos em Metodologia do Ensino Superior. Campinas: Papirus, 2001. p. 137-142.

BRASIL. Lei n o 9.394/96. Lei de Diretrizes e Bases da Educação Nacional, 1996.

CUNHA, Luiz Antonio. Ensino Superior e Universidade no Brasil. In: 500 anos de Educação no Brasil. Organizado por Eliane Marta T. Lopes; Luciano Mendes e Cyntia G. Veiga. (Orgs). Belo Horizonte: Autêntica, 2000

FREIRE, Paulo. Pedagogia da Autonomia: saberes necessários à prática educativa. São Paulo: Paz e Terra, 1996. (Coleção Leitura) 
240 | Ricardo Santos David

FONSECA, Selva Guimarães. Ser professor no Brasil: História Oral de Vida. 2. ed. Campinas: Papirus, 2003.

NÓVOA. António. Desafios do trabalho do professor no mundo contemporâneo. Livreto publicado pelo Sindicato dos Professores de São Paulo, 2007.

RUIZ, M.J.F. O papel social do professor: uma contribuição da filosofia da educação e do pensamento freireano à formação do professor. Revista Iberoamericana de Educación. n.33, 2003 p. 55-70

SAVIANI, Dermeval. A pedagogia no Brasil: história e teoria. Campinas: Autores Associados, 2008.

Recebido em: 14/07/2016

Aceito em: 30/08/2016 